\title{
Fragmentations of Protonated Acetophenones via Intermediate Ion-Molecule Complexes
}

\author{
U. Filges and Hans-Fr. Grützmacher \\ Fakuität für Chemie, Universität Bielefeld, Universitätsstraße 25, D-4800 Bielefeld 1, FRG
}

\begin{abstract}
Protonated acetophenones, substituted with a methoxymethyl group in the para and meta positions, have been generated by electron impact induced fragmentation of the correspondingly substituted 2-phenylpropan-2-ols. The metastable ions, formed in the second field-free region of a VG ZAB 2F mass spectrometer, react unimolecularly by elimination of $\mathrm{CH}_{3} \mathrm{OH}$, formation of $\mathrm{CH}_{3} \mathrm{CO}^{+}$and $\mathrm{CH}_{3} \stackrel{\mathrm{O}}{=} \mathrm{CH}_{2}$ ions, loss of $\mathrm{CH}_{3} \mathrm{COOCH}_{3}$, and loss of $\mathrm{CH}_{2} \mathrm{O}$. The mechanisms of these fragmentations have been elucidated with the aid of deuterated analogues of the protonated acetophenones. It is shown that these reactions are initiated by an endothermic transfer of the proton at the carbonyl group of the protonated acetophenones to the benzene ring. A further migration of the proton to the ether $\mathrm{O}$ atom of the methoxymethyl side-chain leads eventually to the elimination of $\mathrm{CH}_{3} \mathrm{OH}$. Protolytic bond cleavages of either side-chain gives rise to the $\mathrm{CH}_{3} \mathrm{CO}^{+}$and $\mathrm{CH}_{3} \stackrel{+}{\mathrm{O}}=\mathrm{CH}_{2}$ ions. At low internal energies both these ions may be trapped by the aromatic neutral fragment in ion-molecule complexes. Reactions within these complexes result in the energetically favourable losses of $\mathrm{CH}_{3} \mathrm{COOCH}_{3}$ and $\mathrm{CH}_{2} \mathrm{O}$, respectively. With respect to these reactions, the protonated acetophenones behave analogously to the correspondingly substituted and protonated benzaldehydes.
\end{abstract}

\section{INTRODUCTION}

The current theories of bimolecular ion-molecule reactions in the gas phase ${ }^{1}$ have shown that the formation of an intermediate ion-molecule complex is the first reaction step. The ionic and the neutral reactants are bound together in this complex by ion-dipole and ioninduced-dipole forces, but are free to rotate with respect to each other to achieve an optimal orientation for the subsequent chemical reaction. The unimolecular fragmentation reaction of a large ion corresponds to the reversal of a bimolecular association reaction of a smaller ion with a neutral fragment. Hence, by the principle of the microscopic reversibility, a loosely bound ionneutral complex must also be an intermediate of the unimolecular fragmentation. This fact and its consequences for the mechanisms of mass spectrometric fragmentations have been recently discussed by Morton. ${ }^{2}$ However, the ion-neutral complex is the final intermediate of the fragmentation reaction just before the separation of the fragments, and its significance for the mechanism and the kinetics of the total reaction depends very much on the energetics of the system. It is easily seen that the effect of an intermediate ion-neutral complex on the course of a fragmentation reaction will be most important for ions of low internal energy, which react as metastable ions in a mass spectrometer because a large excess energy results in a fast dissociation of the complex. This has indeed been observed. ${ }^{3}$

We have studied the unimolecular reactions of certain protonated aromatic carbonyl compounds by massanalysed ion kinetic energy (MIKE)-spectroscopy. The fragmentations of these metastable ions can be most easily explained by reactions in intermediate ionmolecule complexes. ${ }^{4}$ These reactions have been discussed in detail for protonated benzaldehydes sub- stituted with a methoxymethyl group. ${ }^{5}$ In the present paper, we discuss the results of an analogous investigation of protonated acetophenones. These ions are formed in the ion source of a mass spectrometer by electron impact (EI) induced fragmentation of appropriately substituted 2-phenylpropan-2-ols. It will be shown that the fragmentations of these metastable ions are initiated by the migration of the proton at the carbonyl group to the aromatic moiety and proceed via intermediate ion-molecule complexes.

\section{RESULTS AND DISCUSSION}

Figures 1 and 2 show the $70 \mathrm{eV}$ EI mass spectra of 2-(4-methoxymethylphenyl)propan-2-ol (1) and 2-(3methoxymethylphenyl)propan-2-ol (2), respectively. The molecular ions of 1 and 2 easily fragment by loss of a methyl radical to ions $a(\mathrm{~m} / z 165)$. This is the only fragmentation observed in the MIKE spectra of the molecular ions, and the spectra of deuterated derivatives show that only a $\mathrm{CH}_{3}$ group from the hydroxyisopropyl side-chain is lost (see below). Thus, the ions $a$ correspond to protonated acetophenones substituted with a methoxymethyl group in the para position ( $a_{p}$ from 1$)$ and in the meta position ( $a_{m}$ from 2$)$, respectively. The other abundant ions which are observed in both mass spectra appear at $m / z 133,91,45$ and 43 . The last two ions are formed from the two side-chains of the ions $a$, as indicated by the appropriate mass shifts in the EI mass spectra of deuterated analogues. Ions $m / z 133$ arise from ions $a$ by loss of methanol, while ions $m / z 91$ have to be formed by fragmentations in both side-chains of $a$.

The MIKE spectra of ions $a_{p}$ and ions $a_{m}$, respectively, are shown in Figs 3 and 4. It is clearly seen that 


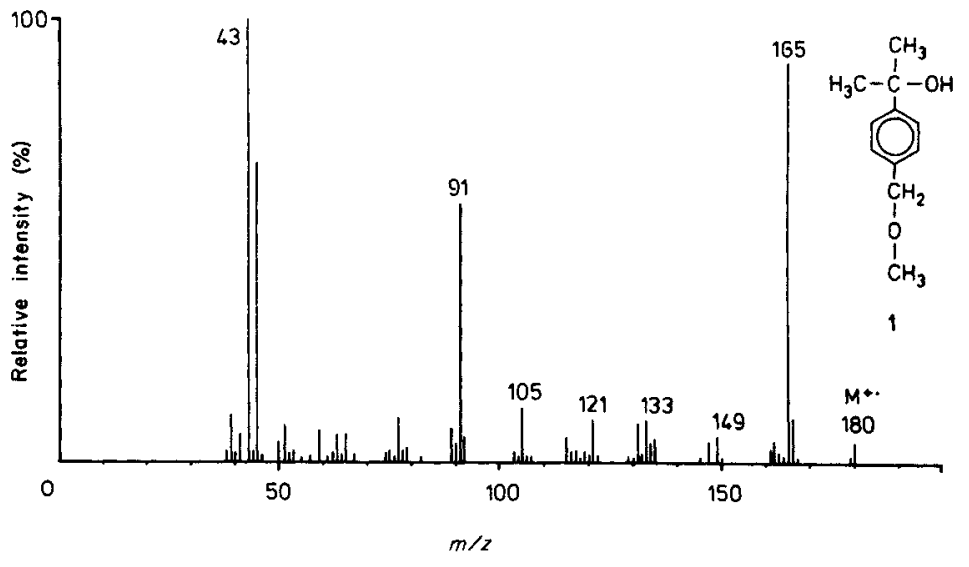

Figure 1. The El mass spectrum of 2-(4-methoxymethyl)propan-2-ol (1).

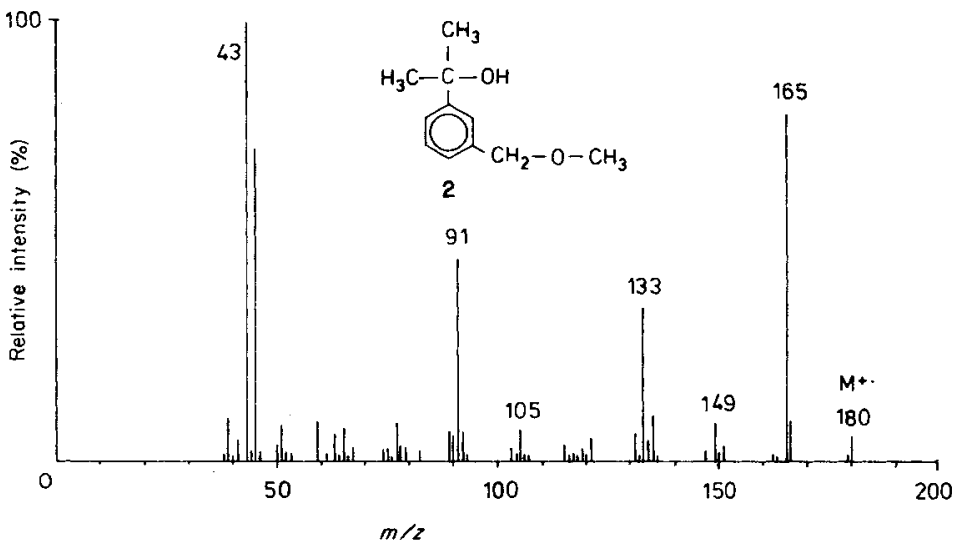

Figure 2. The El mass spectrum of 2-(3-methoxymethyl)propan-2-ol (2).

the ions $m / z 133,91,45$ and 43 indeed arise from the further reactions of ions $a$. In addition to these reactions, the MIKE spectra show the formation of ions $m / z 135$, which corresponds to the elimination of $\mathrm{CH}_{2} \mathrm{O}$ from ions $a$. With the exception of the formation of ions $m / z 43$, the analogous fragmentations have been observed in the MIKE spectra of methoxymethyl substituted protonated benzaldehydes. ${ }^{5}$ In the present case, the mechanisms of these reactions have been studied in the MIKE spectra of deuterated analogues of ions $a$ derived from the deuterated derivatives shown in Scheme 1. The results are presented in Table 1.
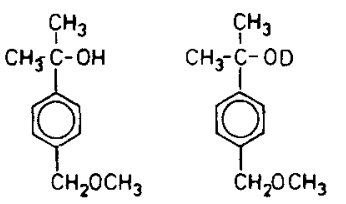

10
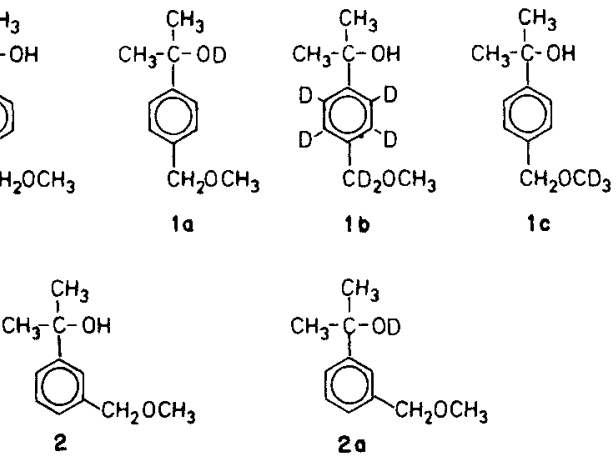

Scheme 1
Ions $m / z 43\left(\mathrm{CH}_{3} \mathrm{CO}^{+}\right)$and $m / z 45\left(\mathrm{CH}_{2}=\stackrel{+}{\mathrm{O}} \mathrm{CH}_{3}\right)$

The signal of the acetyl ions always appears at $\mathrm{m} / \mathrm{z} 43$ in the MIKE spectra, irrespective of the number and the position of the $\mathrm{D}$ atoms in the ions $a_{p}$ derived from 1a-1c. Hence, this ion is formed from the (protonated) acetyl side-chain of ion $a_{p}$ without any H-D exchange. In the MIKE spectrum of $a_{m}$, which is dominated by the signal due to the loss of methanol, the intensity of the acetyl ion peak is very low, and it was not possible to follow any mass shifts in the MIKE spectrum of the deuterated analogue derived from 2a.

The mass of the methoxymethyl cation is completely shifted from $\mathrm{m} / z 45$ to $\mathrm{m} / z 47$ and 48, respectively, in the MIKE spectra of $a_{p}$ derived from $1 \mathbf{b}$ and 1c, but remains at $m / z 45$ for $1 \mathrm{a}$ and $2 \mathrm{a}$. Thus, the methoxymethyl cation arises from ion $a$ by a cleavage of the methoxymethyl side-chain, again without any $\mathrm{H}-\mathrm{D}$ exchange, in agreement with the behaviour of the protonated benzaldehydes substituted with this side-chain. ${ }^{5}$ The formation of the acetyl and methoxymethyl cations can be easily explained by a migration of the proton in ion $a$ from the carbonyl group to the aromatic ring as shown in Scheme 2.

The proton affinity (PA) of a ketone is larger than that of alkylbenzenes (PA(acetone) $=823 \mathrm{~kJ} \mathrm{~mol}^{-1}$; $\mathrm{PA}($ acetophenone $)=859 \mathrm{~kJ} \mathrm{~mol}^{-1} ; \quad \mathrm{PA}$ (toluene $)=$ $794 \mathrm{~kJ} \mathrm{~mol}^{-1} ; \quad \mathrm{PA}(p$-xylene $\left.)=803 \mathrm{~kJ} \mathrm{~mol}^{-1}\right){ }^{6}$ Hence, 


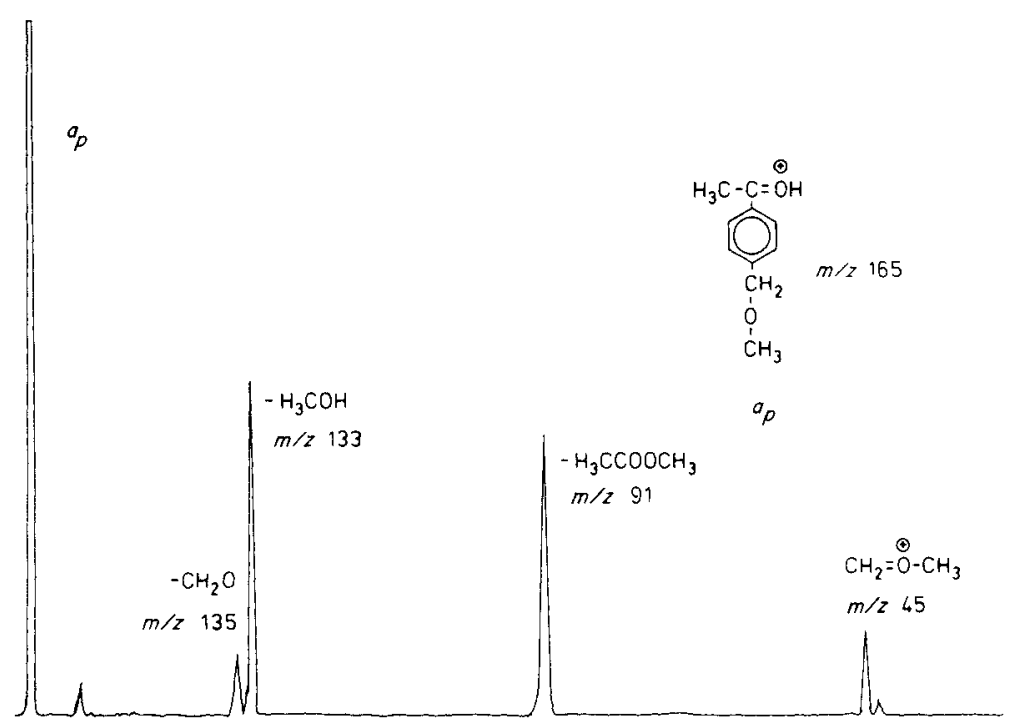

Figure 3. The MIKE spectrum of ions $a_{p}(m / z$ 165; from 1).

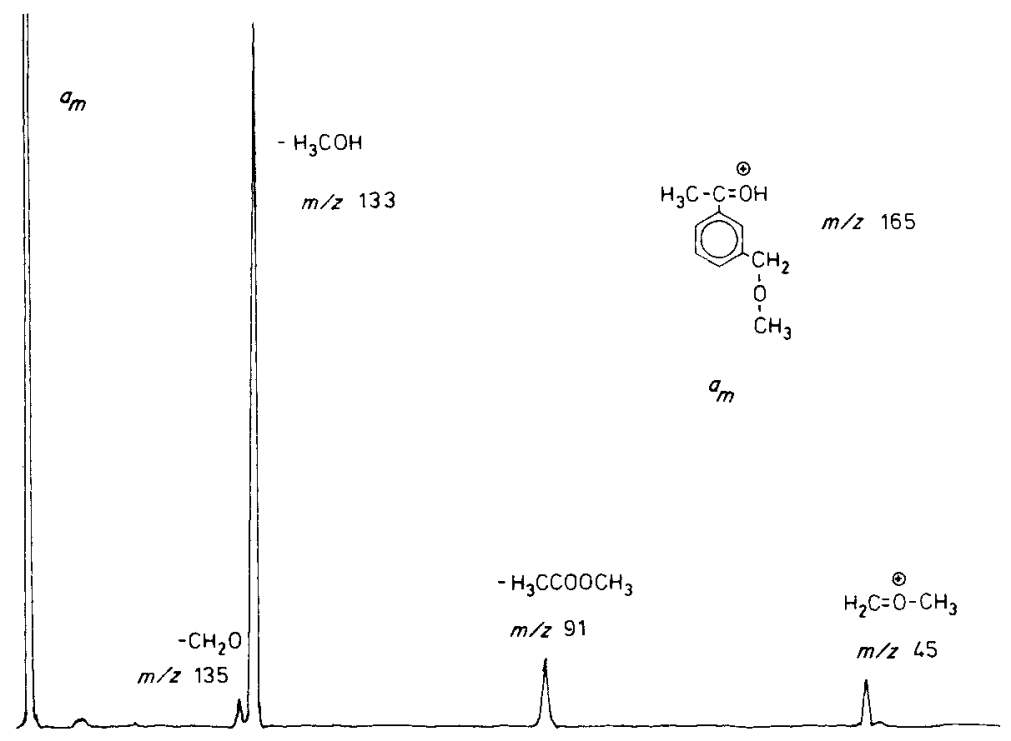

Figure 4. The MIKE spectrum of ions $a_{m}(\mathrm{~m} / \mathrm{z} 165 ;$ from 2$)$.

Table 1. Fragment ion peak intensities in the MIKE spectra of ions $a_{p}$ and $a_{m}$, and their deuterated analogues

\begin{tabular}{|c|c|c|c|c|c|c|}
\hline & \multicolumn{4}{|c|}{$\begin{array}{c}a_{p} \\
\text { from }\end{array}$} & \multicolumn{2}{|c|}{$\begin{array}{c}a_{m} \\
\text { from }\end{array}$} \\
\hline & 1 & 1a & $1 \mathrm{~b}$ & $1 \mathrm{c}$ & 2 & $2 a$ \\
\hline$a-\mathrm{CH}_{3} \mathrm{O}$ & 7 & $5(100 \%)^{a}$ & $<1(<10 \%)$ & $7(100 \%)$ & 3 & $3(100 \%)$ \\
\hline$a-\mathrm{CD}_{2} \mathrm{O}$ & - & - & $8^{b}(>90 \%)$ & - & - & $-(100 \%)$ \\
\hline $\mathrm{a}-\mathrm{CH}_{3} \mathrm{OH}$ & 42 & $30(77 \%)$ & $24(57 \%)$ & - & 84 & $25(30 \%)$ \\
\hline $\mathrm{a}-\mathrm{CH}_{3} \mathrm{OD}$ & - & $9(23 \%)$ & $18(43 \%)$ & - & - & $58(70 \%)$ \\
\hline$a-\mathrm{CD}_{3} \mathrm{OH}$ & - & - & - & $39(100 \%)$ & - & - \\
\hline $\mathrm{a}-\mathrm{CH}_{3} \mathrm{COOCH}_{3}$ & 40 & $37(100 \%)$ & $37(100 \%)$ & - & 7 & $9(100 \%)$ \\
\hline $\mathrm{a}-\mathrm{CH}_{3} \mathrm{COOCD}_{3}$ & 一 & - & - & $39(100 \%)$ & - & - \\
\hline $\mathrm{CH}_{2}=\mathrm{OCH}_{3}$ & 11 & $10(100 \%)$ & $10(100 \%)$ & - & 6 & $5(100 \%)$ \\
\hline $\mathrm{CH}_{2}=\mathrm{OCD}_{3}$ & - & - & - & $14(100 \%)$ & & \\
\hline $\mathrm{CH}_{3} \mathrm{CO}^{+}$ & 1 & $2(100 \%)$ & $1(100 \%)$ & $2(100 \%)$ & & \\
\hline
\end{tabular}

a Values in parentheses refer to the deuterium distribution on neutral fragments.

be peak of $a_{p}-\mathrm{CD}_{2} \mathrm{O}$ coincides with that of $a_{p}-\mathrm{CH}_{3} \mathrm{OH}$. The loss of $\mathrm{CD}_{2} \mathrm{O}$ was estimated from the excess of the intensity at $a_{p}-32$. 


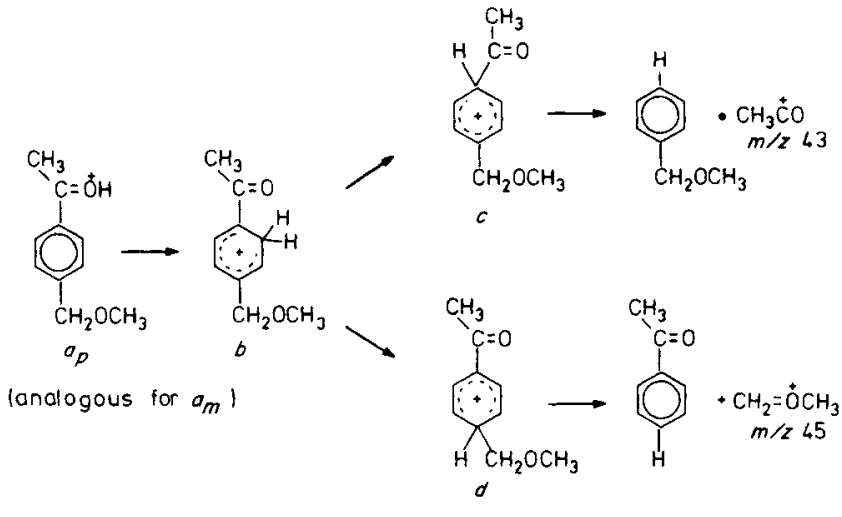

Scheme 2

the transfer of the proton from the carbonyl group in $a$ to the benzene ring in $b$ can only occur in excited ions a. Migration of the proton into either of the two ipso positions, and cleavage of the corresponding side-chain, gives rise to ions $m / z 43$ and 45 , respectively. Note that intermediate ion-molecule complexes are formed before the complete dissociation and that the ions $m / z 43$ and 45 give rise to very large peaks in the normal EI mass spectrum (Figs 1 and 2) but correspond to rather small signals in the MIKE spectra (Figs 3 and 4). Obviously, the dissociation via Scheme 2 is preferred only by ions $a$ with a large amount of excess energy, while metastable ions $a$ with a small amount of internal energy prefer the reaction channels leading to ions $m / z 133$ and 91 , in agreement with the expected influence of the internal energy on the reactions of ion-neutral complexes. ${ }^{3}$

Scheme 2 corresponds to the analogous reaction of protonated benzaldehydes. ${ }^{5}$ However, for the protonated acetophenones, the proton transfer to the aromatic ring is followed by dissociations to ions $m / z 43$ and 45 , while the protonated benzaldehydes form ions $\mathrm{m} / \mathrm{z} 45$ only, and no formyl ions $m / z 29$. This different behaviour is due to the different reaction energies in the two systems. The formyl cation is rather unstable and the sum of the heats of formation of the reaction products of $743 \mathrm{~kJ} \mathrm{~mol}^{-1} \quad\left(\Delta H_{f}\left(\mathrm{CHO}^{+}\right)=815 \mathrm{~kJ} \mathrm{~mol}^{-1} ;^{7 \mathrm{a}}\right.$ $\left.\Delta H_{f}\left(\mathrm{C}_{6} \mathrm{H}_{5} \mathrm{CH}_{2} \mathrm{OCH}_{3}\right)=-72 \mathrm{~kJ} \mathrm{~mol}^{-1}\right)^{8}$ for the dissociation of the protonated benzaldehyde into this ion and benzyl methyl ether is much larger than the $634 \mathrm{~kJ} \mathrm{~mol}^{-1}\left(\Delta H_{f}\left(\mathrm{CH}_{3} \mathrm{O}=\mathrm{CH}_{2}\right)=657 \mathrm{~kJ} \mathrm{~mol}^{-1} ;{ }^{7 \mathrm{~b}}\right.$ $\left.\Delta H_{f}\left(\mathrm{C}_{6} \mathrm{H}_{5} \mathrm{CHO}\right)=-23 \mathrm{~kJ} \mathrm{~mol}^{-1}\right)^{8}$ for the dissociation into the methoxymethyl cation and benzaldehyde. In contrast, the sum of the heats of formation of the dissociation products of the two pathways of Scheme 2 is $569 \mathrm{~kJ} \mathrm{~mol}^{-1}\left(\Delta H_{f}\left(\mathrm{CH}_{3} \mathrm{CO}^{+}\right)=641 \mathrm{~kJ} \mathrm{~mol}^{-1} ;^{7 \mathrm{c}}\right)$ and $567 \mathrm{~kJ} \mathrm{~mol}^{-1}\left(\Delta \mathrm{H}_{f}\left(\mathrm{C}_{6} \mathrm{H}_{5} \mathrm{COCH}_{3}\right)=-90 \mathrm{~kJ} \mathrm{~mol}^{-1}\right){ }^{8}$, respectively.

\section{Ions $m / z 133\left(a-\mathrm{CH}_{3} \mathrm{OH}\right)$}

Loss of methanol is the most important reaction of ions $a_{p}$ and $a_{m}$, in agreement with the behaviour of the analogous protonated benzaldehydes. ${ }^{5}$ This reaction is also initiated by a migration of the proton at the carbonyl group of $a$ on to the aromatic ring as shown in Scheme 3.

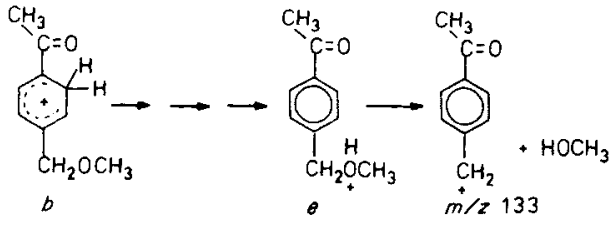

Scheme 3

The PA of an ether $\mathrm{O}$ atoms is larger than the PA of alkylbenzenes $\left(\mathrm{PA}\left(\mathrm{CH}_{3} \mathrm{OCH}_{3}\right)=804 \mathrm{~kJ} \mathrm{~mol}^{-16}\right)$. Hence, the further migration of the proton in the intermediate $b$ to the ether group is energetically favoured, and methanol is eventually lost from the intermediate $e$. The migration of the proton from the carbonyl group to the ether group across the benzene ring is accompanied by some H-D exchange in the deuterated ions $a$ derived from $\mathbf{1 b}, \mathbf{1 b}$ and $2 \mathrm{a}$. The values for the losses of $\mathrm{CH}_{3} \mathrm{OH}$ and $\mathrm{CH}_{3} \mathrm{OD}$, respectively, given in Table 1, never reach the statistical limit which corresponds to $20 \%$ loss of $\mathrm{CH}_{3} \mathrm{OD}$ in the cases of $1 \mathrm{a}$ and $2 \mathrm{a}$ and $80 \%$ loss of $\mathrm{CH}_{3} \mathrm{OD}$ in the case of $1 \mathrm{~b}$, assuming complete scrambling of the proton at the carbonyl group and the four hydrogen atoms at the benzene ring. The experimental results given in Table 1 show a preferred elimination of the proton or deuteron originally at the carbonyl group of $a$, which cannot be explained by an isotope effect, but indicates a migration across the aromatic ring without any exchange. The same observation has been made for the elimination of methanol from the analogous substituted and protonated benzaldehydes. ${ }^{5}$ It is obvious from these data that the migration of the proton across the aromatic ring occurs by an additional mechanism besides the 'ring walk'. This competing mechanism will be discussed more in detail in a forthcoming paper dealing with the reactions of protonated naphthyl ketones. ${ }^{9}$

The sum of the heats of formation of the products of the reaction of Scheme 3 has been estimated to be $569 \mathrm{~kJ} \mathrm{~mol}^{-1} \quad\left(\Delta \mathrm{H}_{f}\left(\left[\mathrm{CH}_{3} \mathrm{COC}_{6} \mathrm{H}_{4} \mathrm{CH}_{2}\right]^{+}\right)=\right.$ $\left.770 \mathrm{~kJ} \mathrm{~mol}^{-1} ;{ }^{10} \Delta \mathrm{H}_{f}\left(\mathrm{CH}_{3} \mathrm{OH}\right)=-201 \mathrm{~kJ} \mathrm{~mol}^{-1}\right)^{8}$. Thus, the reaction enthalpy of Scheme 3 is similar to those of both pathways of Scheme 2 . While this explains the competing formation of ions $m / z 43$ and 45 with methanol elimination, the large intensity difference in favour of the loss of methanol must be due to kinetic effects.

\section{Ions $m / z 91\left(a-\mathrm{CH}_{3} \mathrm{COOCH}_{3}\right)$}

While the rather large intensity of the $m / z 91$ ion peak, both in the normal EI mass spectra of 1 and 2 and in the MIKE spectra of the ions $a$, can be understood in terms of the high stability of the $\left[\mathrm{C}_{7} \mathrm{H}_{7}\right]^{+}$ions, the formation of these ions from metastable ions $a$ in an apparently one-step reaction is surprising, and the mechanism of this fragmentation is very interesting. If the ions $m / z 91$ are formed by consecutive losses of methanol and ketene with methanol elimination as the first reaction step, the label distribution of the methanol elimination from deuterated ions $a$ should be preserved in the final step and should also appear in the final reaction products. However, the data given in Table 1 show clearly that this is not the case and that the elimination of methanol and the elimination of a fragment of 


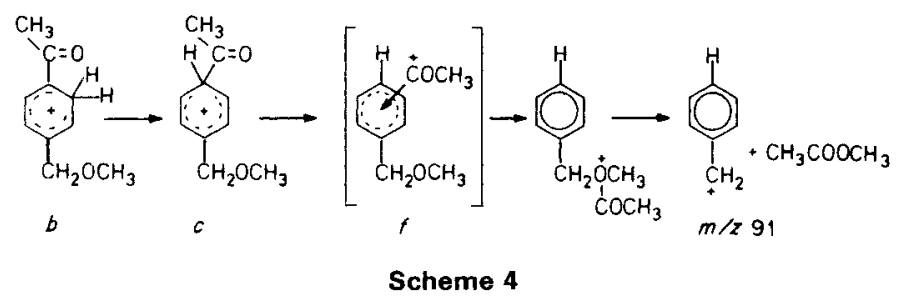

$74 \mathrm{u}$ (supposed to be $\mathrm{CH}_{3} \mathrm{COOH}_{3}$ ) occur independently of each other. The most significant result is obtained by the reactions of ions $a_{p}$ derived from $1 \mathbf{b}$ (Table 1 ). While approximately equal amounts of $\mathrm{CH}_{3} \mathrm{OH}$ and $\mathrm{CH}_{3} \mathrm{OD}$ are lost from this hexadeuterated ion $a_{p}$, only $\mathrm{CH}_{3} \mathrm{COOCH}_{3}$ is eliminated without any $\mathrm{H}-\mathrm{D}$ exchange. On the other hand, consecutive losses of ketene and methanol with ketene elimination as the first reaction step are very unlikely. The elimination of ketene from $a$ is energetically unfavourable and is not observed because it cannot compete with the elimination of methanol. Thus, the situation is similar to the fragmentation of methoxymethyl substituted protonated benzaldehydes via loss of $\mathrm{HCOOCH}_{3}, \mathrm{COC}^{5}$ and the elimination of $\mathrm{CH}_{3} \mathrm{COOCH}_{3}$ from ions $a$ occurs very probably by an analogous mechanism depicted in Scheme 4.

The important reaction step of this mechanism is the collapse of the ipso-protonated intermediate $c$ into the ion-molecule complex $f$. Calculating the attractive electrostatic forces within the complex by the classical formula, $^{2}$ and assuming a rather long distance of $3 \AA$ between the $\mathrm{CH}_{3} \mathrm{CO}^{+}$ion and the centre of the aromatic ring, gives a stabilization of the complex $f$ of $186 \mathrm{~kJ} \mathrm{~mol}^{-1}$ with respect to its dissociation products. Furthermore, the estimated heat of formation of $c$ is $559 \mathrm{~kJ} \mathrm{~mol}^{-1}, 11$ and the dissociation of $c$ into the complex $f$ is exothermic. Thus, at least some of the complexes $f$ are formed with insufficient energy for a fast direct dissociation. The acetyl ion in $f$ is free to migrate towards the ether group, which eventually leads to the dissociation of the complex into $\left[\mathrm{C}_{7} \mathrm{H}_{7}\right]^{+}$and $\mathrm{CH}_{3} \mathrm{COOCH}_{3}$ by an ion-molecule reaction within the complex. The sum of the heats of formation of these products is $462 \mathrm{~kJ} \mathrm{~mol}^{-1}\left(\Delta H_{f}\left(\left[\mathrm{C}_{7} \mathrm{H}_{7}\right]^{+}\right)=859 \mathrm{~kJ} \mathrm{~mol}^{-1} ;^{12}\right.$ $\left.\Delta H_{f}\left(\mathrm{CH}_{3} \mathrm{COOCH}_{3}\right)=-397 \mathrm{~kJ} \mathrm{~mol}^{-1}{ }^{8}\right)$, and the relative reaction enthalpy is much lower than that for a direct dissociation of the complex $f$ (see Scheme 2). However, the ion-molecule reaction within the complex, corresponding to a $\mathrm{S}_{\mathrm{E}} 2$ reaction at the ether $\mathrm{O}$ atom, has a 'tight' transition state and the direct dissociation of the complex $f$ is preferred at high internal energy.

\section{Ions $m / z 135\left(a-\mathrm{CH}_{2} \mathrm{O}\right)$}

Protonated benzaldehydes with a methoxymethyl substituent fragment by loss of formaldehyde which is formed from the $\mathrm{CH}_{2} \mathrm{O}$ moiety of the side-chain and not from the terminal $\mathrm{CH}_{3} \mathrm{O}$ group. ${ }^{5}$ In the present case of protonated acetophenones, the metastable ions $a$ also eliminate $\mathrm{CH}_{2} \mathrm{O}$ (see Figs 3 and 4), and the results from the labelled analogues prove (Table 1) that it is again the internal $\mathrm{CH}_{2} \mathrm{O}$ moiety of the side-chain which is lost. This follows from the observation that ions $a$ derived from 1c with the terminal $\mathrm{CD}_{3} \mathrm{O}$ group still lose $\mathrm{CH}_{2} \mathrm{O}$, while those from $1 \mathrm{~b}$ lose $\mathrm{CD}_{2} \mathrm{O}$, since the signal is buried under the large signal for methanol loss and no signal for loss of $30 \mathrm{u}$ is observed in the MIKE spectrum. Thus, the mechanism for this fragmentation is the same as that for the protonated benzaldehydes ${ }^{5}$ involving an ionneutral complex formed by a methoxymethyl cation and an acetophenone molecule as shown in Scheme 5.

The ion-molecule reaction occurring within the complex $g$ corresponds to a methyl group transfer from the methoxymethyl cation to the carbonyl group of acetophenone. This methylating ability of the methoxymethyl cation is known from its bimolecular reactions. ${ }^{13}$ Again, the transition state for the methyl group transfer in the complex $g$ is much more 'tight' than that for a direct dissociation of $g$, and the latter process is preferred if the complex $g$ contains sufficient internal energy.

\section{CONCLUSIONS}

All reactions of protonated acetophenone ions $a$, when generated as metastable ions by EI induced fragmentations from suitable precursors, start with a transfer of the proton from the carbonyl group to the benzene ring. Hence, the ion $b$ is the common reactive configuration of all five fragmentations observed, and its formation probably corresponds to the common transition state with the highest energy barrier. This would explain the competition of reactions with rather different reaction enthalpies during the fragmentation of $a$.

The exact structure of $b$, and of the transition state for the endothermic proton transfer, is not known. It seems plausible to assume a 1,4-proton transfer from the carbonyl group to the ortho position of the benzene ring, in view of the unfavourable energetics of $1,3-\mathrm{H}$ shifts or two subsequent $1,2-\mathrm{H}$ shifts in related systems. ${ }^{14}$ However, the results of the labelling study for the methanol elimination show that there is at least one
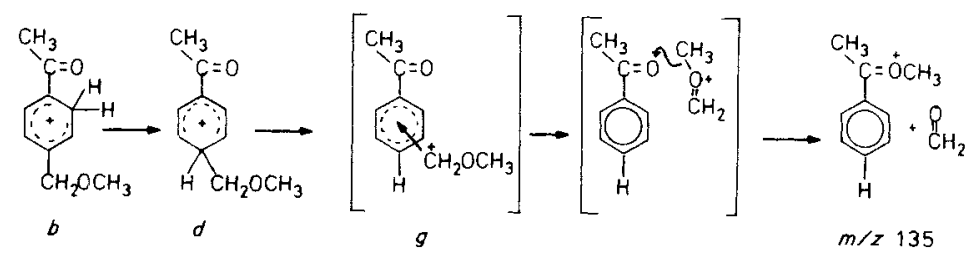

Scheme 5 
additional pathway for a direct proton transfer from the carbonyl group across the benzene ring to the ether group.

The most characteristic feature of the reactions of $b$ is the protolytic cleavage of the two side-chains (Scheme 2). This corresponds to the well-known deacetylation and dealkylation of adequately substituted benzene in very acidic solutions. A very interesting result for these reactions in the gas phase is the capture of the acetyl cation and the methoxymethyl cation, respectively, by the aromatic neutrals to form the ion-neutral complexes $f$ (Scheme 4) and $g$ (Scheme 5). Subsequent ionmolecule reactions within the complexes lead to fragmentations which are much more energetically favourable than the direct dissociation of the complex. The same reactions as for $b$ have been observed for metastable protonated benzaldehydes substituted with a methoxymethyl group. ${ }^{5}$ Thus, the formation of ionneutral complexes at low internal energies by a protolytic bond cleavage is a general reaction possibility of substituted aromatic ions. ${ }^{5,9}$

Two effects remain to be studied in more detail. First, the mechanism of the proton transfer across the aromatic ring preceding the loss of methanol, without any exchange between the hydrogens at the different positions, has to be investigated. The role of this migration mechanism apparently depends on the relative orientation of the side-chains and can be studied in more detail with the aid of the various positional isomers of naphthalene derivatives. Second, the ease of the protolytic bond cleavages in ions $b$ indicates assistance to the bond-breaking process by the energy gain resulting from the ion-neutral complex formation, which is mostly due to the polarizability of the aromatic fragment. The polarizability increases with the size of the aromatic system. Hence, one can expect that complex formation and fragmentations via ion-neutral complexes as intermediates will be of even more importance in the lowenergy reactions of protonated naphthyl aldehydes and ketones.

\section{EXPERIMENTAL}

\section{Mass spectrometry}

The $70 \mathrm{eV}$ EI mass spectra were obtained with a MAT 311A/SS 200 mass spectrometer/data system under the following conditions: electron energy, $70 \mathrm{eV}$; emitter current, $3 \mathrm{~mA}$; acceleration voltage, $3 \mathrm{kV}$; ion source temperature, $180^{\circ} \mathrm{C}$.

The reactions of metastable ions (MIKE spectra) were investigated with a VG ZAB $2 \mathrm{~F}$ mass spectrometer under the following conditions; electron energy, $70 \mathrm{eV}$; electron trap current, $50 \mu \mathrm{A}$; acceleration voltage, $6 \mathrm{kV}$; standard EI/CI ion source; ion source temperature, $\sim 180^{\circ} \mathrm{C}$. The reactions were observed by focusing the relevant ion into the second field-free region and varying the electrostatic field.

\section{Compounds}

2-(4-Methoxymethylphenyl)propan-2-ol(1) and 2-(3methoxymethylphenyl)propan-2-ol (2) were prepared from the corresponding chloromethyl substituted derivatives by treatment with $\mathrm{CH}_{3} \mathrm{ONa}$ in $\mathrm{CH}_{3} \mathrm{OH}$ and purified by Kugelrohr distillation at $110^{\circ} \mathrm{C}$ and 0.1 Torr. 2-(4-Chloromethylphenyl)propan-2-ol and 2-(3chloromethylphenyl)propan-2-ol were obtained from the corresponding benzoic acids ${ }^{15}$ by conversion into the acid chlorides followed by the Grignard reaction with $\mathrm{CH}_{3} \mathrm{MgI}$.

The hydrogen atom of the hydroxyl group in 1 and $\mathbf{2}$ was exchanged for a deuterium atom by addition of excess $\mathrm{D}_{2} \mathrm{O}$ to yield 1a and 2a immediately before the mass spectrometric measurements. The hexadeuterated derivative $1 \mathrm{~b}$ was synthetized from $d_{8}$-toluene by acetylation with $\mathrm{CH}_{3} \mathrm{COCl}$ and $\mathrm{AlCl}_{3}$ in dry $\mathrm{CS}_{2}$ to yield $d_{7}$-4-methylacetophenone. This was brominated with NBS in the usual way to $d_{7}$-4-bromomethylacetophenone, which was converted into $1 \mathrm{~b}$ by treated with $\mathrm{CH}_{3} \mathrm{ONa} / \mathrm{CH}_{3} \mathrm{OH}$.

2 - (4 - Trideuteromethoxymethylphenyl)propan - 2 ol (lc) was prepared from the corresponding chloromethyl derivative by treatment with $\mathrm{CD}_{3} \mathrm{ONa} / \mathrm{CD}_{3} \mathrm{OH}$.

\section{Acknowledgements}

We thank the Deutsche Forschungsgemeinschaft for financial support of this work. Additional financial support was given by the Fonds der Chemischen Industrie, which is gratefully acknowledged. We also thank Mr E. Gärtner very much for his technical assistance during the mass spectrometric measurements.

\section{REFERENCES}

1. T. Su and M. T. Bowers, in Gas Phase Ion Chemistry, ed. by M. T. Bowers, Vol. 1. Academic Press, New York (1979); T. F. Magnere and P. Kebarle, in lonic Processes in the Gas Phase, ed. By M. A. Almoster-Ferreira, NATO ASI Series C. Reidel, Dordrecht (1984).

2. T. H. Morton, Tetrahedron 38, 3195 (1983).

3. C. E. Hudson and D. J. McAdoo, Int J. Mass Spectrom. Ion Processes 59, 325 (1984); C. E. Hudson and D. J. McAdoo, in Advances in Mass Spectrometry 1985, ed. by J. F. J. Todd, Part B, p. 797. Wiley, Chichester (1986).

4. U. Filges, Diplomarbeit, Universität Bielefeld (1984); U. Filges and H. F. Grützmacher, in Advances in Mass Spectrometry 1985 ed. by J. F. J. Todd, Part B, p. 763. Wiley, Chichester (1986).
5. U. Filges and H. F. Grützmacher, Org. Mass Spectrom. 21, 673 (1986).

6. Sh. G. Lias, J. F. Liebman and R. D. Levin, J. Phys. Chem. Ref. Data 13, 695 (1984).

7. (a) H. M. Rosenstock, K. Draxl, B. W. Steiner and J. T. Herron, J. Phys. Chem. Ref. Data 6, Suppl. 1 (1977); (b) F. P. Lossing, J. Am. Chem. Soc. 99,7526 (1977); (c) R. H. Staley, R. D. Wieting and J. L. Beauchamp. J. Am. Chem. Soc. 99, 5964 (1977).

8. S. W. Benson, F. R. Cruickshank, D. M. Golden, G. R. Haugen, H. E. O'Neal, A. S. Rodgers, R. Shaw and R. Walsh, Chem. Rev. 69, 279 (1969).

9. U. Filges and H. F. Grützmacher, Int. J. Mass Spectrom., lon Proc., submitted. 
10. Calculated by MNDO.

11. Calculated by MNDO. Using $\Delta \mathrm{H}_{f}\left(\mathrm{CH}_{3} \mathrm{COC}_{6} \mathrm{H}_{4} \mathrm{CH}_{2} \mathrm{OCH}_{3}\right)=$ $-250 \mathrm{~kJ} \mathrm{~mol}^{-1}$ (by increments ${ }^{8}$ ) and $\mathrm{PA}\left(\mathrm{C}_{6} \mathrm{H}_{6}\right)=759 \mathrm{~kJ} \mathrm{~mol}^{-16}$, one obtains $-520 \mathrm{~kJ} \mathrm{~mol}^{-1}$ for the heat of formation of $b$ or $c$.

12. R. G. McLoughlin, J. D. Morrison and J. C. Traeger, Org. Mass Spectrom. 14, 104 (1979)
13. J. L. Beauchamp and R. C. Dunbar, J. Am. Chem. Soc. 92, 1477 (1970); R. van Dorn and N. M. M. Nibbering, Org. Mass Spectrom. 13, 527 (1978).

14. L. L. Griffin, K. Holden, C. E. Hudson and D. J. McAdoo, Org. Mass Spectrom. 21, 175 (1986), and references cited therein.

15. C. Barkenbus and J. B. Holtzclaw, J. Am. Chem. Soc. 47, 2189 (1925). 